Jennifer Ngaire Heuer, The Family and the Nation. Gender and Citizenship in Revolutionary France, 1789-1830

Ithaca, Cornell University Press, 2005, VIII-256 p., ISBN

978-0-8014-4286-5, 34.95 \$.

\title{
Anne Verjus
}

\section{OpenEdition}

\section{Journals}

Édition électronique

URL : https://journals.openedition.org/ahrf/11288

DOI : $10.4000 /$ ahrf. 11288

ISSN : 1952-403X

Éditeur :

Armand Colin, Société des études robespierristes

Édition imprimée

Date de publication : 1 septembre 2007

Pagination : 215-217

ISSN : 0003-4436

Référence électronique

Anne Verjus, « Jennifer Ngaire Heuer, The Family and the Nation. Gender and Citizenship in Revolutionary France, 1789-1830». Annales historiques de la Révolution française [En ligne], 349 | juillet-septembre 2007, mis en ligne le 29 décembre 2009, consulté le 01 juillet 2021. URL : http:// journals.openedition.org/ahrf/11288 ; DOI : https://doi.org/10.4000/ahrf.11288 
tableau vivant des représentations de La Fayette et de son rôle dans la guerre d'indépendance.

Lentreprise de réhabilitation de La Fayette pourra ne pas convaincre, mais il faut sans doute la voir comme un témoignage de la passion que portait son auteur à la période révolutionnaire.

Marc BELISSA

Jennifer Ngaire Heuer, The Family and the Nation. Gender and Citizenship in Revolutionary France, 1789-1830, Ithaca, Cornell University Press, 2005, VIII-256 p., ISBN 978-0-8014-4286-5, 34.95\$.

The Family and the Nation pose la question du lien entre classe de sexe et droits et devoirs patriotiques. La famille et la Nation sont des entités juridiques qui, toutes deux, imposent des devoirs à leurs membres, au premier rang desquels l'obéissance à l'autorité souveraine. Les problèmes engendrés par cette double allégeance vont être considérables lorsque, dès les premières années de la Révolution, famille et nation vont entrer en concurrence : comment doit agir une épouse prise entre l'injonction étatique de demeurer sur le territoire français et le devoir d'obéissance à son époux qui l'enjoint d'émigrer avec elle ? À quelle aune, au regard des peines encourues, la justice doit-elle mesurer la part de responsabilité de cette épouse obéissante et pourtant traître à sa patrie ? Telles sont quelquesunes des questions soulevées par le livre de Jennifer Ngaire Heuer qui retrace le processus par lequel la famille a progressivement été distincte de la nation, reconstruite, au sortir de la Terreur, comme une sphère à part, protégée de toute intrusion étatique, et dont les membres dépendants, tels les épouses, les enfants mineurs et les domestiques, ont acquis, au prix de l'anéantissement de leur citoyenneté, le privilège de ne plus devoir obéissance qu'à une seule autorité : celle du pater familias.

Le livre de Jennifer Heuer, qui est professeur d'histoire à l'Université de Massachusetts, Amherst, est une version retravaillée d'un $\mathrm{PhD}$ soutenu à l'université de Chicago, en 1998, sous la direction du professeur William Sewell (Foreigners, families and citizens : contradictions of national citizenship in France, 1789-1830). Il s'articule autour de trois parties et huit chapitres : I. La famille de la nation (1. Nouveaux contrats de parenté et citoyenneté, 1789-1793; 2. Le devoir pour la patrie avant tout : la Terreur); II. Vers une nation de familles : transitions vers la fin des années 1790 (3. Pères et étrangers ; 4. Genre et émigration reconsidérés) ; III. La solution napoléonienne et ses limites (5. Attacher l'épouse de Cain : le Code civil napoléonien ; 6. En regardant vers le passé : les conséquences de la mort civile ; 7. En regardant vers l'avenir : les femmes et l'application de la loi de citoyenneté ; 8. Immigration, mariage et citoyenneté pendant la Restauration).

Pendant la premic̀re période, qui s'étend de 1789 à 1794, la Nation est la première famille des citoyens. C'est à ce titre que tous et toutes sont requis de faire cesser tout lien qui pourrait entraver l'exercice des devoirs dus à la mère patrie ; et que c'est bien en vain que les femmes d'émigrés, ou émigrées elles mêmes, plaident leur innocence. Elles sont 14000 , nous dit J. Heuer, à avoir émigré ; et 50000 chefs de famille. Dès 1792, celles qui sont revenues trouvent des défenseurs de leur cause ; ceux-ci arguent que les femmes, comme les domestiques, ne sauraient abandonner leur patrie, ne sauraient trahir puisqu'ils et elles sont sans utilité dans la nation, 
" en dehors de la société ». En vain : les législateurs lient encore clairement, à cette date, dépendance économique, fidélité familiale et identité politique. " En 1791 comme en 1792, les révolutionnaires étaient conscients des liens émotionnels et pragmatiques qui lient les couples suspects, et doutaient le plus souvent que les femmes mariées soient, ou puissent être, complètement indépendantes de leur époux » (p. 42). Les émigrées qui prétendent avoir été contraintes par la puissance maritale se voient donc répondre qu'en la matière, seuls les actes parleront : et que pour être effective, la désolidarisation passera par le divorce.

La femme n'est donc jamais nulle, politiquement, dans ces premières années de la Révolution : juridiquement mineure, économiquement dépendante, elle fait partie d'une communauté familiale à laquelle elle est tout entière identifiée, à laquelle elle est soupçonnée de vouloir apporter son concours, et de se montrer solidaire en toutes circonstances. Au même moment, en Amérique, les épouses des ennemis de la République sont autorisécs à circuler librement. Présumées inoffensives, membres de la famille avant d'être membres de la nation, elles ne sont pas moins solidaires des intérêts de la communauté conjugale ; mais c'est une solidarité qui n'est pas censée induire d'actes politiques dangereux pour la nation.

" Le mariage est une décision consciente de s'associer à la communauté politique et sociale de son époux ", déclare-t-on en 1794, alors que vient d'être décrétée une exclusion généralisée des ex-nobles.

C'est au lendemain de la Terreur que basculent les plaidoiries : les femmes mettent de plus en plus en avant leur nullité militaire et politique pour récuser le soupçon de trahison patriotique. Cette nullité sert des objectifs : elle est notamment un argument majeur pour remettre la main sur les biens de la communauté, mis sous séquestre du fait de l'émigration du chef de famille.

Mais elle a aussi des conséquences : les étrangers ne pourront plus devenir français par le mariage avec une Française ; toute femme suivra, désormais, le statut de son époux, sa nationalité, son choix de domicilc. Seul le veuvage lui rendra ses droits de Française ; les femmes perdront, enfin, le titre de citoyenne, celui de citoyen étant désormais strictement réservé aux détenteurs des droits politiques, distincts des détenteurs de la nationalité. Une ultime conséquence sera la création d'une sphère privée, protégée de l'intervention de l'État et qu'illustre le cas magnifiquement rapporté par Jennifer Heuer, de Suzanne Lepelleticr. Deux positions s'affrontent dans ce procès célèbre des années 1797-1798: celle, vouée à l'échec, des frères de Suzanne, désireux que l'État intervienne, en lieu et place de son père assassiné, pour annuler le choix matrimonial de leur sœur ; et celle, finalement victorieuse, de Chazal qui, pour défendre la liberté de décision de la jeune orpheline, prône paradoxalement la création d'une famille protégée de toute intervention étatique, protectrice de ses membres par l'autorité de son chef.

Parmi bien d'autres cas qui viennent illustrer la problématique de Jennifer Heuer, l'un des plus instructifs est celui de $\mathbf{M}^{\| 1 \mathrm{te}}$ Lange et de $\mathrm{M}$. Hoppé, deux parents qui s'empoignent pour obtenir la garde de leur petite fille de 18 mois; des avocats aussi célèbres que Portalis, Duveyrier et Cambacérès interviennent pour déterminer de qui cette enfant naturelle doit suivre le statut et la nationalité, de son père étranger ou de sa mère française. Les arguments du défenseur de $\mathrm{M}^{11 \mathrm{ci}}$ Lange seront les plus intéressants : sans possibilité de léguer sa nationalité, la mère ne peut qu'invoquer la protection de la nation, pour elle en tant que Française, et pour sa fille en tant que mineure. C'est la Nation qui ici prend le pas sur les droits naturels du père et non d'hypothétiques droits de la mère; c'est en tant que membres 
"dépendants" de la nation que cette femme et sa fille peuvent réclamer leurs droits de citoyennes, en l'occurrence le droit à une protection; et c'est en tant que membres de la nation médiatisées par la représentation des hommes de la famille que leur avocat, Duveyricr, défend ce qu'il appelle leurs droits civils et politiques.

Les derniers chapitres, qui portent sur la mort civile, la disjonction entre le droit de la nationalité et les droits de la citoyenneté, sont d'autres illustrations de cette progressive formation d'une sphère juridique délimitée par les droits et devoirs du mariage, société hiérarchique placée sous la responsabilité du pater familias et protégée de toute « intrusion » de l'État dans ses affaires.

Entre la famille et la nation, il y a désormais le voile d'une autorité paternelle restaurée dans des limites certes plus étroites, puisqu'elle ne s'applique plus qu'à l'épouse et aux enfants mineurs; mais qui s'exerce désormais dans le secret du giron familial, véritable enclave dans la nation, protégée autant que protectrice. Le Code civil inaugure cette ère au cours de laquelle "les législateurs et les administrateurs du XIX' siècle, comme les hommes et femmes ordinaires, vont considérer le mariage des femmes comme une allégeance volontaire à la communauté nationale représentée par leur époux" (p. 196). On ne saurait micux dire pour conclure ce très bel ouvrage qui non seulement apporte des éléments empiriques de toute première importance dans le champ de l'histoire juridique et sociale de la citoyenneté et de la nationalité, mais parvient également à démontrer l'intérêt d'articuler les contradictions de l'ancien et du nouveau, ici du familial et du national, pour mettre à jour les équilibres qui ont présidé à la mise en place de la société démocratique. Après les ouvrages désormais classiques de Geneviève Fraisse, Lynn Hunt et Suzanne Desan, Jennifer Heuer fait la preuve que « l'histoire genrée du politique » est décidément entrée dans l'ère de la maturité.

Anne VerJus

Cesare Vetter (éd.), La felicità è une idea nuova in Europa. Contributo al lessico della rivoluzione francese, Tomo I, Trieste, Edizione Università di Trieste, 2005, 270 pages, ISBN 88-8303-183-0, $20 €$.

Au cours des années 1970 et 1980 , le laboratoire de lexicologie politique de l'ENS-Saint-Cloud, constitue, à l'initiative d'Annie Geffroy et de l'équipe " $18^{\mathrm{c}}$ Révolution française " une textothèque " Révolution française " avec des textes issus de divers auteurs et de publications centrales de la période révolutionnaire (Marat, Hébert, Robespicrre, Jacques Roux, les Déclarations des droits, les discours à l'Assemblée, les Archives parlementaires, etc.). Rien d'exhaustif donc, mais de nombreux éléments lexicaux disponibles pour des études quantitatives et qualitatives qui ont nourri partiellement, en association avec la partie "Révolution française », du Trésor de la langue française, la publication de monographies lexicales dans le Dictionnaire des usages socio-politiques (1770-1815), disponible sous la forme de huit volumes publićs entre 1985 et 2006, et dont nous continuons à assurer la co-direction avec Raymonde Monnier et Marie-France Piguet.

Constituée sur la base d'enregistrements «vicillis ", mais partiellement mis à jour, cette textothèque demeure encore active pour une part, par exemple avec les corpus Marat (L'Ami du peuple) et Hébert (Le Père Duchesne) à l'initiative d'André Salem, Agnès Steuckardt et moi-même. Mais la majeure part de ses éléments est en 